ORIGINAL ARTICLE

\title{
Effects on alcohol related fatal crashes of a community based initiative to increase substance abuse treatment and reduce alcohol availability
}

\author{
R W Hingson, R C Zakocs, T Heeren, M R Winter, D Rosenbloom, W DeJong
}

Injury Prevention 2005;11:84-90. doi: 10.1136/ip.2004.006353

See end of article for authors' affiliations

.....................

Correspondence to: Professor R Hingson, Boston University School of Public Health and Center to Prevent Alcohol-related Problems Among Young People, 715 Allbany Street, Boston, MA 02118; rhingson@mail.nih.gov
Objective: This analysis tested whether comprehensive community interventions that focus on reducing alcohol availability and increasing substance abuse treatment can reduce alcohol related fatal traffic crashes.

Intervention: Five of 14 communities awarded Fighting Back grants by The Robert Wood Johnson Foundation to reduce substance abuse and related problems attempted to reduce availability of alcohol and expand substance abuse treatment programs (FBAT communities). Program implementation began on 1 January 1992.

Design: A quasi-experimental design matched each program community to two or three other communities of similar demographic composition in the same state.

Main outcome measures: The ratio of fatal crashes involving a driver or pedestrian with a blood alcohol concentration of $0.01 \%$ or higher, $0.08 \%$ or higher, or $0.15 \%$ or higher were examined relative to fatal crashes where no alcohol was involved for 10 years preceding and 10 years following program initiation. Results: Relative to their comparison communities, the five FBAT communities experienced significant declines of $22 \%$ in alcohol related fatal crashes at $0.01 \%$ BAC or higher, $20 \%$ at $0.08 \%$ or higher, and $17 \%$ at $0.15 \%$ or higher relative to fatal crashes not involving alcohol.

Conclusions: Community interventions to reduce alcohol availability and increase substance abuse treatment can reduce alcohol related fatal traffic crashes.
$\mathrm{D}$ espite declines over the past two decades, annual alcohol related traffic deaths exceed 17000 in the US Comprehensive community interventions, that publicize enforcement of drunk driving laws and restrict alcohol availability, can reduce alcohol related traffic deaths and injuries, ${ }^{2}$ and have been recommended by the National Institute of Alcohol Abuse and Alcoholism and the Institute of Medicine to combat excessive college and underage drinking and related problems. ${ }^{3}$ The Saving Lives Program ${ }^{5}$ organized task forces in six mid-size Massachusetts towns to reduce driving after drinking and improve traffic safety. Interventions included school based peer education, media campaigns, enhanced police enforcement, responsible server training, alcohol outlet surveillance, and beer keg registration. ${ }^{5}$ Compared with the rest of Massachusetts, Saving Lives Program communities experienced statistically significant declines in self-reported driving after drinking among 16 to 19 year olds, traffic related injuries, total fatal crashes, and alcohol related traffic fatalities.

The Community Prevention Trial ${ }^{6}$ organized coalitions in three towns in California and South Carolina to encourage responsible beverage service, zoning restrictions to reduce alcohol outlet density, and stricter enforcement of underage drinking and drunk driving laws. ${ }^{6}$ Statistically significant declines were found in alcohol consumption, driving after drinking, alcohol related traffic crashes, and emergency department alcohol related assault injuries, relative to comparison sites.

Communities Mobilizing for Change, ${ }^{7}$ sought to reduce alcohol sales and availability through non-commercial sources to people below the legal drinking age. Compliance checks monitored the proportion of underage purchase attempts resulting in alcohol sales, and written feedback informed merchants of potential penalties for continued sale.
Bar and restaurant alcohol sales to youth and the proportion of youth seeking to buy alcohol declined by $25 \%$, and the proportion of older teens providing alcohol to younger teens declined by $17 \%$. Drinking by people under 21 declined significantly as did driving after drinking and disorderly conduct violations.

Expanding substance abuse treatment services may also reduce alcohol related traffic crashes. According to national survey data, $70 \%$ of adults who reported driving in an alcohol related traffic crash in the past year met DSM-IV criteria for alcohol dependence. ${ }^{1}$ Evaluations of brief motivational treatment interventions targeting emergency department and trauma center patients with alcohol related injuries have noted decreases in self-reported driving after drinking ${ }^{8-12}$ and driving under the influence violations. ${ }^{12}{ }^{13} \mathrm{~A}$ review of screening and brief interventions in primary care settings also reported reductions in drinking and, in some studies, a reduction in injuries. ${ }^{14}$ Systematic reviews of treatment of those with alcohol use disorders or drunk driving convictions found motor vehicle crashes and injury reductions associated with treatment. ${ }^{15}{ }^{16}$ However, the population level impact of these interventions has not been tested.

Numerous community coalitions address illicit drug and alcohol abuse. Beginning in the 1990s, the US Center for Substance Abuse Prevention and the US Office of National Drug Control Policy have each funded over 400 local antidrug coalitions. ${ }^{17}{ }^{18}$ Community Anti-Drug Coalitions of America boasts a membership of over 5000 local coalitions. Although many coalitions attempt to expand treatment services and reduce alcohol availability, whether or not this

Abbreviations: BAC, blood alcohol concentration; FARS, Fatality Analysis Reporting System; FB, Fighting Back; RWJF, Robert Wood Johnson Foundation. 


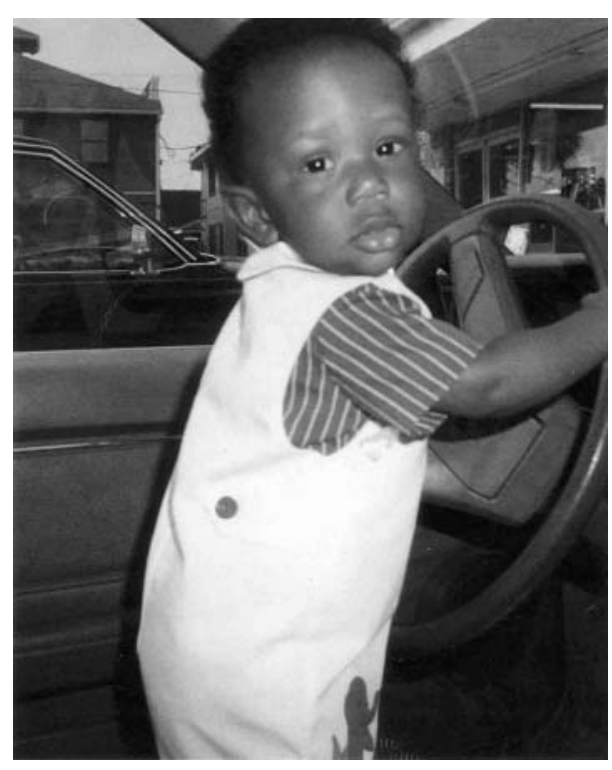

This article is dedicated to Courtney Birch who in 1986 at age 21 months was fatally injured by an intoxicated repeat drunk driving offender who was driving with a suspended license.

combined strategy decreases alcohol related traffic fatalities at the community level has not been tested and is the focus of this study.

\section{METHODS}

\section{The Fighting Back program}

We examined a subset of communities funded by the Robert Wood Johnson Foundation's (RWJF) Fighting Back (FB) program to ameliorate substance abuse and related problems. The RWJF issued a call for FB proposals in 1989. ${ }^{19}{ }^{20}$ Over 330 were reviewed by RWJF staff, FB National Advisory Committee members, (nationally known experts convened by the RWJF), and the FB National Office at Vanderbilt University (funded by the RWJF to provide technical assistance to the sites). Proposals were evaluated in terms of severity of the problem, past efforts and community leader commitment to address the problem, proposed comprehensive, multifaceted approach, community support, and ability to match RWJF funds with external sources.

Fifteen communities were awarded planning grants from 1990 to 1991, 12 communities received implementation grants from 1992 through 1997, and five continuous funding until 2002.

Community grants ranged from $\$ 300000$ to $\$ 450000$ in 1990-91 for intervention planning, and \$3-4 million from 1992-97, and \$200 000 up to \$3 million from 1998-2002 for implementation. Sites convened citizen task forces to develop coordinated, comprehensive strategies to heighten awareness about the issue, and improve prevention, early identification, treatment, and aftercare services. Communities had latitude to craft their own initiatives. Seven programs targeted entire communities and five a portion of the community (table 1). Gallup, New Mexico targeted six municipalities in three counties encompassing four Native American nations that spanned 15000 square miles.

The RWJF sponsored an outcome evaluation, with 12 of the FB communities matched with two or three comparison sites within the same $\operatorname{state}^{21}$ (table 1) (Gallup, New Mexico was excluded due to its vast geography and low household telephone ownership). The evaluation focused on three general population telephone surveys in both FB and

\begin{tabular}{|c|c|c|}
\hline Target & Fighting Back sites & Comparison sites \\
\hline \multirow[t]{7}{*}{$\begin{array}{l}\text { Entire } \\
\text { community }\end{array}$} & Columbia, SC & $\begin{array}{l}\text { Charleston, SC (North) } \\
\text { Greenville, SC }\end{array}$ \\
\hline & Little Rock, AK & $\begin{array}{l}\text { Fort Smith, AK } \\
\text { Pine Bluff, AK }\end{array}$ \\
\hline & Newark, NJ & $\begin{array}{l}\text { Camden, NJ } \\
\text { Jersey City, NJ }\end{array}$ \\
\hline & New Haven, CT & $\begin{array}{l}\text { Bridgeport, CT } \\
\text { Hartford, CT } \\
\text { Waterbury, CT }\end{array}$ \\
\hline & Santa Barbara, CA & $\begin{array}{l}\text { Carlsbad, CA } \\
\text { Redondo Beach, CA }\end{array}$ \\
\hline & Vallejo, CA & $\begin{array}{l}\text { San Bernadino, CA } \\
\text { Stockton, CA }\end{array}$ \\
\hline & Worcester, MA & $\begin{array}{l}\text { Fall River, MA } \\
\text { Lowell, MA } \\
\text { Springfield, MA }\end{array}$ \\
\hline \multirow[t]{7}{*}{$\begin{array}{l}\text { Partial } \\
\text { community }\end{array}$} & Charlotte, NC & $\begin{array}{l}\text { Greensboro, NC } \\
\text { Raleigh, NC } \\
\text { Winston-Salem, NC }\end{array}$ \\
\hline & Kansas City, MO & $\begin{array}{l}\text { Columbia, MO } \\
\text { Springfield, MO } \\
\text { St Lovis, MO }\end{array}$ \\
\hline & Milwaukee, WI & Madison, WI \\
\hline & & Racine, WI \\
\hline & San Antonio, TX & $\begin{array}{l}\text { Dallas, TX } \\
\text { Fort Worth, TX }\end{array}$ \\
\hline & & Houston, TX \\
\hline & $\begin{array}{l}\text { Washington, DC } \\
\text { (Marshall Heights) }\end{array}$ & $\begin{array}{l}\text { Baltimore, MD } \\
\text { Washington, DC (Central) }\end{array}$ \\
\hline
\end{tabular}

comparison communities. Response rates were 59\% in 1995 , $58 \%$ in 1997, and $49 \%$ in 1999. Respondents were asked about their substance use, treatment/prevention knowledge, and perceptions about substance abuse in their neighborhoods, but not about driving after drinking. Respondents in FB and comparison communities did not differ on sociodemographic characteristics. However, significantly smaller percentages of FB respondents were white. Of 12 substance use outcomes, the FB communities showed significant declines relative to comparison communities in the proportion of respondents and drinkers who were alcohol dependent. The greatest declines occurred in Kansas City and Milwaukee.

\section{FB focused site selection: FBAT communities}

We retrospectively abstracted program and evaluation documents and interviewed key staff and task force members to identify FB communities that devoted the greatest effort to limit alcohol availability and expand treatment services (FBAT communities). Table 2 identifies actions taken to limit alcohol availability and expand availability and treatment services and usage.

Table 2 identifies five of the 12 FB sites that initiated eight or more actions to restrict alcohol availability and expand treatment (FBAT communities): Kansas City, MO; Milwaukee, WI; San Antonio, TX; and Santa Barbara, CA; and Vallejo, CA. They were classified as having a concentrated effort to achieve these goals because they targeted both expanding treatment and reducing alcohol availability (left side of table), whereas the other sites tended to implement fewer actions, most of which were aimed at treatment (right side of table). Three FBAT communities (Milwaukee, WI; Santa Barbara, CA; Vallejo, CA) targeted the entire city and only Milwaukee was not funded through 2002. Only one site (Santa Barbara) undertook efforts to mount extra enforcement of driving under the influence laws. 


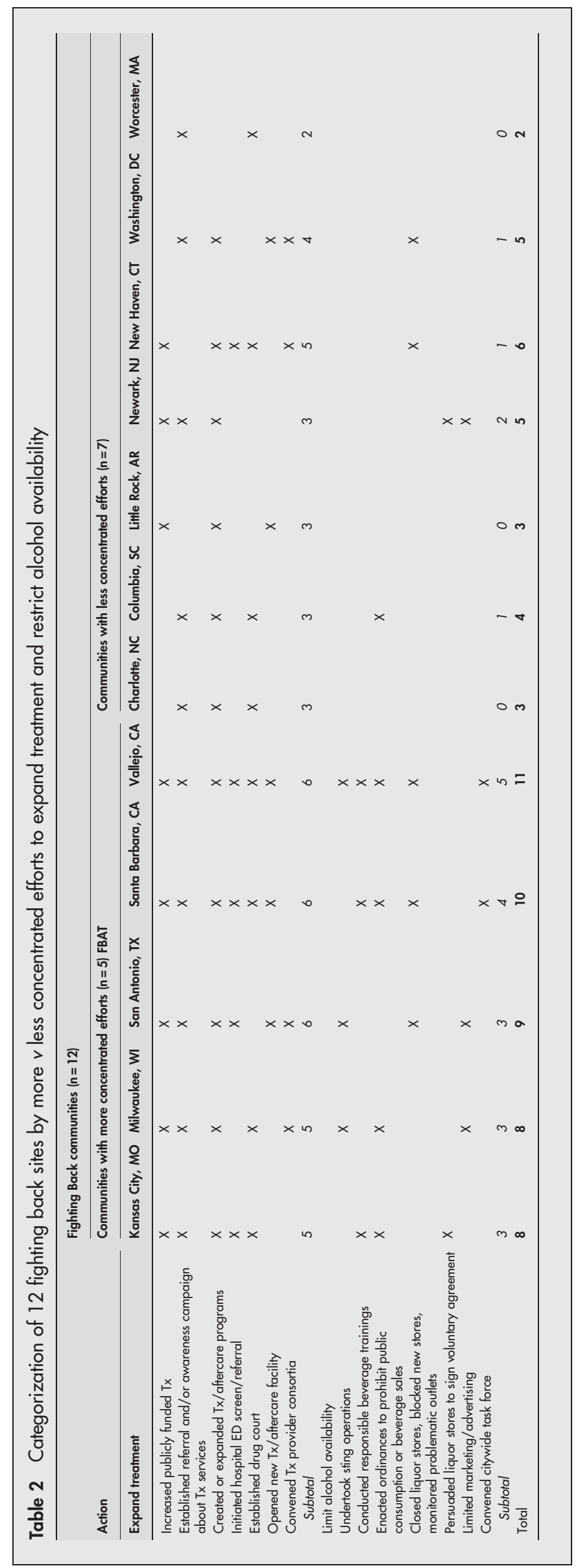

\section{Program evaluation design}

For comparison, the five selected FBAT communities were each matched by the RWJF sponsored evaluation team with two or three neighborhoods in communities of similar population size or demographic composition, from the same state so that they shared similar weather, economic conditions, alcohol regulations, and drinking driving laws. The multiple matched comparison design inoculated against diffusion effects, decreased the likelihood that a historical artifact in one comparison community could result in significant differences attributable to FB, and enhanced statistical power.

The Fighting Back program started on 1 January 1992. In each pair of communities, our analysis examined 10 years before and 10 years after program initiation: 1 January 1982 to 30 December 1991 and 1 January 1992 to 30 December 2001 , respectively.

\section{Analytic strategy}

We examined changes in alcohol related traffic fatality statistics from pre to post program years in each FBAT community versus its matched comparison sites. We then performed a meta-analysis across the set of five comparisons to determine the mean effect of the FB community based interventions.

We analyzed annual fatal crash data reported by the National Highway Traffic Safety Administration's Fatality Analysis Reporting System (FARS). To assess alcohol involvement in fatal crashes, FARS uses actual blood test results when available, but then imputes estimates for untested drivers (ranging from $0.01 \%$ to $0.99 \%$ BAC, at $0.01 \%$ intervals) based on associated crash characteristics identified in states with high levels of testing. Using FARS data for alcohol tested drivers in fatal crashes combined with imputed data for non-tested drivers allowed us to make accurate estimates of the percent of crashes involving alcohol in each community yearly, even if the actual percent of drivers tested for alcohol varied over time.

We examined both per crash and per driver measures of alcohol involvement. For the per crash calculation, we examined the odds that a fatal crash involved alcohol by taking the ratio of the number of crashes involving either a driver or pedestrian with a positive alcohol level to the number of crashes not involving alcohol. For the per driver calculation, we examined the ratio of the number of drivers with positive BAC to the number of drivers with zero BAC. We performed separate per crash and per driver analyses for alcohol involvement at $0.01 \%, 0.08 \%$ (the legal limit in most states), and $0.15 \%$ BAC.

The ratios of alcohol related fatal crashes relative to nonalcohol fatal crashes were examined instead of the absolute number of alcohol related fatal crashes, to correct for the long term downward trend in alcohol related fatal crashes over the past two decades and any changes in exogenous variables that might influence overall fatal crash trends such as economy, safety characteristics of vehicles and highways, and the price of fuel.

Within each community, we calculated the percent change in the odds of an alcohol related fatal crash (or driver) from the pre to post program period. This percent change is related to the odds ratio describing the change from the pre to post program period:

$$
\begin{aligned}
& \% \text { change }=100 \% \times[(\text { odds }(\text { post })-\text { odds }(\text { pre })] / \text { odds }(\text { pre }) \\
& =100 \% \times[\text { OR }-1]
\end{aligned}
$$

Because the FARS provides fatal crash data at the community (as opposed to the neighbourhood) level we examined entire communities. For each FBAT/comparison 
site pairing, we estimated the program effect as the adjusted OR describing the change in alcohol related crashes (or drivers) in the FBAT community, adjusting for change in the matched comparison sites. This adjusted odds ratio is the ratio of the ORs from the FBAT and comparison sites, and is equal to the FBAT program effect OR from a logistic regression predicting alcohol involvement from indicator variables representing community (FBAT $v$ Comparison) and time (pre $v$ post FBAT initiation). Significance of the FBAT program effect OR is described through 95\% confidence intervals based on the standard errors of the log OR.

Meta-analytic methods calculated overall relative change due to interventions across the set of five FBAT communities, relative to their comparison communities. ${ }^{22}$ The overall effects are weighted averages of the individual community effects, so that communities with more crashes are weighted more heavily. A test of heterogeneity across the five FBAT/ comparison site pairings was conducted to test the significance of community-to-community variation in effect sizes. Regardless of the observed variation in effect, the relative change in the proportion of fatal crashes involving BACs at $0.01 \%, 0.08 \%, 0.15 \%$ or higher were treated as random effects in the meta-analyses. A pooled estimate and standard error for the natural log of the program effect OR from each state pair were calculated. These estimates and their 95\% confidence intervals were transformed back to the scales of odds ratios for presentation.

\section{RESULTS}

\section{Pre-program comparison}

Over the 10 pre-program years, in the five FBAT communities and their matched comparison communities, similar proportions of fatal crashes involved alcohol (table 3 ) and drivers in fatal crashes with positive blood alcohol levels (data available upon request). The proportion of fatal crashes that involved alcohol and drivers with positive alcohol levels were higher during the pre-program years in the three FBAT communities that targeted the entire community relative to their controls. There were no significant differences between most FBAT and comparison communities with respect to the trend in alcohol involvement over the 10 pre-program years. However, in the four years before the start of the program, alcohol involvement in fatal crashes rose significantly in Vallejo relative to its comparison communities. This would make it more difficult to identify program effects in that community relative to its comparison sites.

\section{Alcohol related fatal crashes}

Table 3 displays detailed results evaluating the FBAT program on alcohol involvement in fatal crashes at $0.01 \%$ BAC. Table 4 displays summary results evaluating the effect of the FBAT program on alcohol involvement in fatal crashes at the $0.01 \%$, $0.08 \%$, and $0.15 \%$ BAC level. For each FBAT/comparison sites pairing, the number and odds of alcohol related crashes are given, as well as the adjusted OR describing the estimated FBAT program effect. The table also gives the meta-analytic pooled estimates for the FBAT program effect.

Based on the meta-analytic results, relative to comparison communities, the five FBAT communities experienced a $22 \%$ decline in the odds of an alcohol related fatal crash at $0.01 \%$ $\mathrm{BAC}$ or higher during the 10 program years compared with the previous 10 years $(p=0.01)$. Those five communities also experienced declines of $20 \%$ at $0.08 \%$ BAC or higher $(\mathrm{p}<0.001)$ and $17 \%$ at $0.15 \%$ BAC or higher $(p=0.02)$. The test of heterogeneity showed that effect sizes for alcohol related fatal crashes at $0.01 \%$ BAC or higher varied significantly among the five FBAT communities. Effect size variability across those communities also approached significance at $0.08 \%$ BAC and higher.

Table 3 Fatal crashes involving a driver or pedestrian with $0.01 \%$ BAC or higher 10 years before and 10 years after initiation of the Fighting Back programs

\begin{tabular}{|c|c|c|c|c|c|c|}
\hline \multirow[b]{2}{*}{ Fighting Back FBAT comparison communities } & \multicolumn{6}{|c|}{ Ratio of fatal crashes involving drivers or pedestrians with BAC $0.01 \%+v 0.00 \%$} \\
\hline & \multicolumn{2}{|c|}{$\begin{array}{l}\text { Before FB } 0.01 \%+v \text { no } \\
\text { alcohol ratio number }\end{array}$} & \multicolumn{2}{|c|}{$\begin{array}{l}\text { After FB } 0.01 \%+v \text { no alcohol } \\
\text { ratio number }\end{array}$} & \multirow{2}{*}{$\begin{array}{l}\% \text { Change } \\
-15 \%\end{array}$} & \multirow{2}{*}{$\begin{array}{l}\text { Program effect OR } \\
(95 \% \mathrm{CI})\end{array}$} \\
\hline Kansas City (FB) & 1.52 & $443 / 291$ & 1.29 & $359 / 278$ & & \\
\hline Columbia, Springfield, St Louis & 1.11 & $337 / 303$ & 1.14 & $348 / 305$ & $+3 \%$ & $(0.61-1.12)$ \\
\hline Milwaukee (FB) & 1.44 & $252 / 175$ & 0.72 & $161 / 224$ & $-50 \%$ & 0.55 \\
\hline Madison, Racine & 1.32 & $74 / 56$ & 1.20 & $59 / 49$ & $-9 \%$ & $(0.31-0.98)$ \\
\hline San Antonio (FB) & 1.90 & $794 / 418$ & 1.52 & $653 / 430$ & $-20 \%$ & 0.95 \\
\hline Dallas, Ft Worth, Houston & 1.85 & $3146 / 1700$ & 1.56 & $2472 / 1587$ & $-16 \%$ & $(0.79-1.15)$ \\
\hline Santa Barbara (FB) & 1.95 & $41 / 21$ & 1.61 & $37 / 23$ & $-18 \%$ & 0.87 \\
\hline Carlsbad, Redondo Beach, Santa Monica & 1.04 & $117 / 112$ & 0.99 & $80 / 81$ & $-5 \%$ & $(0.37-2.02)$ \\
\hline Vallejo (FB) & 1.32 & $58 / 44$ & 0.74 & $35 / 47$ & $-44 \%$ & 0.69 \\
\hline $\begin{array}{l}\text { San Bernardino, Stockton } \\
\text { Pooled results, five FB communities targeting } \\
\text { alcohol availability and increased treatment } \\
\text { (FBAT) }\end{array}$ & 1.06 & $265 / 251$ & 0.86 & $212 / 247$ & $-19 \%$ & $(0.63-0.76)$ \\
\hline Total FB & 1.67 & $1588 / 949$ & 1.24 & $1245 / 1002$ & & 0.78 \\
\hline \multirow[t]{2}{*}{ Total comparison } & 1.63 & $3939 / 2422$ & 1.40 & $3171 / 2269$ & & $(0.64,0.95)$ \\
\hline & & & \multicolumn{2}{|c|}{ Heterogeneity: $p=0.04$} & Program effect: $p=0.01$ & $\begin{array}{l}\text { Relative reduction: } \\
\downarrow 22 \%\end{array}$ \\
\hline \multicolumn{7}{|l|}{$\begin{array}{l}\text { Pooled results, three FB programs covering entire } \\
\text { community (FBAT) }\end{array}$} \\
\hline Santa Barbara, Vallejo, Milwaukee & 1.46 & $351 / 240$ & 0.79 & $233 / 294$ & & 0.69 \\
\hline \multirow[t]{2}{*}{ Comparison } & 1.09 & $456 / 419$ & 0.93 & $351 / 377$ & & $(0.63,0.76)$ \\
\hline & & & \multicolumn{2}{|c|}{ Heterogeneity: NS } & $\begin{array}{l}\text { Program effect: } \\
p<0.0001\end{array}$ & $\begin{array}{l}\text { Relative reduction: } \\
\downarrow 31 \%\end{array}$ \\
\hline \multicolumn{7}{|l|}{$\begin{array}{l}\text { Seven FB communities not targeting alcohol } \\
\text { availability and increased treatment }\end{array}$} \\
\hline Total FB & 1.08 & $1013 / 941$ & 0.86 & $905 / 1047$ & & 1.31 \\
\hline \multirow[t]{2}{*}{ Comparison } & 1.05 & $1225 / 1169$ & 0.75 & $944 / 1266$ & & $(0.93,1.85)$ \\
\hline & & & \multicolumn{2}{|c|}{ Heterogeneity: $p=0.002$} & Program effect: NS & $\begin{array}{l}\text { Relative change: } \\
\uparrow 31 \%\end{array}$ \\
\hline
\end{tabular}




\begin{tabular}{|c|c|c|c|}
\hline $\begin{array}{l}\text { Individual FBAT } \\
\text { communities }\end{array}$ & $\begin{array}{l}\text { Program effect at } \\
0.01 \%+B A C \text { OR }(95 \% \mathrm{Cl})\end{array}$ & $\begin{array}{l}\text { Program effect at } \\
0.08 \%+\text { BAC OR }(95 \% \text { Cl) }\end{array}$ & $\begin{array}{l}\text { Program effect at } \\
0.15 \%+B A C \text { OR }(95 \% \mathrm{Cl})\end{array}$ \\
\hline Kansas City & $0.83(0.61-1.12)$ & $0.86(0.63-1.18)$ & $0.80(0.57-1.13)$ \\
\hline Milwaukee & $0.55(0.31-0.98)$ & $0.57(0.31-1.04)$ & $0.54(0.28-1.04)$ \\
\hline San Antonio & $0.95(0.79-1.15)$ & $0.95(0.79-1.16)$ & $0.95(0.77-1.18)$ \\
\hline Santa Barbara & $0.87(0.37-2.02)$ & $0.99(0.41-2.38)$ & $1.01(0.39-2.60)$ \\
\hline Vallejo & $0.69(0.63-0.76)$ & $0.63(0.50-0.80)$ & $0.58(0.39-0.87)$ \\
\hline Pooled effect* & $0.78(0.64-0.95)$ & $0.80(0.71-0.92)$ & $0.83(0.71-0.97)$ \\
\hline \multirow{2}{*}{$\begin{array}{l}\text { Five FBAT communities } \\
\text { targeting alcohol } \\
\text { availability and increased } \\
\text { treatment }\end{array}$} & Relative reduction $22 \%$ & Relative reduction $20 \%$ & Relative reduction $17 \%$ \\
\hline & $p=0.01$ & $p<0.001$ & $p=0.02$ \\
\hline \multirow{3}{*}{$\begin{array}{l}\text { Pooled effect* } \\
\text { Three FBAT programs } \\
\text { covering entire community }\end{array}$} & $0.69(0.63-0.76)$ & $0.64(0.52-0.79)$ & $0.61(0.44-0.84)$ \\
\hline & Relative reduction $31 \%$ & Relative reduction $36 \%$ & Relative reduction $39 \%$ \\
\hline & $p<0.001$ & $p<0.001$ & $p=0.003$ \\
\hline \multirow{2}{*}{$\begin{array}{l}\text { Seven FB communities not } \\
\text { targeting alcohol } \\
\text { availability and increased } \\
\text { treatment* }\end{array}$} & $1.31(0.93-1.85)$ & $1.17(0.97-1.41)$ & $1.11(0.90-1.37)$ \\
\hline & $\begin{array}{l}\text { Relative increase } 31 \% \\
\text { NS }\end{array}$ & $\begin{array}{l}\text { Relative increase } 17 \% \\
\text { NS }\end{array}$ & $\begin{array}{l}\text { Relative increase } 11 \% \\
\text { NS }\end{array}$ \\
\hline \multicolumn{4}{|c|}{$\begin{array}{l}\text { *Pooled analysis of five } \mathrm{FB} \text { communities showed significant heterogeneity of program effect at } \mathrm{BAC} \text { levels of } \\
0.01 \%+\text { and } 0.08 \%+\text {. Pooled analysis of three } \mathrm{FB} \text { communities showed significant heterogeneity of program effec } \\
\text { at BAC levels of } 0.01 \%+\text { and } 0.08 \%+\text {. Pooled analysis of } \mathrm{FB} \text { communities not targeting alcohol availability and } \\
\text { increased treatment showed significant heterogeneity of effect at BAC levels of } 0.01 \%+\text {. } \\
\text { NS, not significant. }\end{array}$} \\
\hline
\end{tabular}

In the three FBAT communities targeting the entire city, alcohol related fatal crashes declined $31 \%$ at $0.01 \%$ BAC or higher, $(\mathrm{p}<0.001), 36 \%$ at $0.08 \%$ BAC or higher $(\mathrm{p}<0.0001)$, and $39 \%$ at $0.15 \%$ BAC or higher $(p<0.003)$ (table 4$)$. There were no significant differences or heterogeneity of effect across these three communities. Proportional declines in alcohol related fatal crashes were equal to or greater than those observed when all five FBAT communities were examined as a group.

In the other FB communities with less concentrated efforts to reduce alcohol availability and increase substance abuse treatment, there were no declines in the odds of alcohol related fatal crashes at $0.01 \%, 0.08 \%$, or $0.15 \%$ BAC or higher, relative to comparison communities.

\section{Drivers in fatal crashes}

Based on the meta-analysis, relative to comparison communities, the five FBAT communities experienced an $11 \%$ decline, in the odds of drivers in fatal crashes having $0.01 \%$ $\mathrm{BAC}$ or higher, relative to zero $\mathrm{BAC}$, during the 10 program years compared with the previous 10 years $(p=0.05)$ (table 5). They experienced non-significant declines of $9 \%$ among drivers with $0.08 \%$ BAC or higher $(p=0.17)$ and $12 \%$ at $0.15 \%$ BAC or higher $(p=0.07)$. Variability in effect sizes

\begin{tabular}{|c|c|c|c|}
\hline $\begin{array}{l}\text { Individual FBAT } \\
\text { communities }\end{array}$ & $\begin{array}{l}\text { Program effect at } \\
0.01+\% \text { BAC OR }(95 \% \mathrm{Cl})\end{array}$ & $\begin{array}{l}\text { Program effect at } \\
0.08 \%+B A C \text { OR }(95 \% \mathrm{Cl})\end{array}$ & $\begin{array}{l}\text { Program effect at } \\
0.15 \%+B A C \text { OR }(95 \% \mathrm{Cl})\end{array}$ \\
\hline Kansas City & $0.78(0.60-1.01)$ & $0.78(0.60-1.03)$ & $0.68(0.49-0.93)$ \\
\hline Milwaukee & $0.61(0.36-1.01)$ & $0.65(0.38-1.11)$ & $0.54(0.28-1.03)$ \\
\hline San Antonio & $1.00(0.85-1.16)$ & $1.02(0.86-1.19)$ & $1.01(0.84-1.21)$ \\
\hline Santa Barbara & $0.82(0.39-1.71)$ & $1.06(0.48-2.36)$ & $0.99(0.38-2.58)$ \\
\hline Vallejo & $0.72(0.49-1.06)$ & $0.74(0.47-1.16)$ & $0.65(0.35-1.21)$ \\
\hline Pooled effect, * & $0.89(0.79-1.00)$ & $0.91(0.81-1.04)$ & $0.88(0.75-1.02)$ \\
\hline \multirow{2}{*}{$\begin{array}{l}\text { Five FBAT communities } \\
\text { targeting alcohol } \\
\text { availability and increased } \\
\text { treatment }\end{array}$} & Relative reduction $11 \%$ & Relative reduction $9 \%$ & Relative reduction $12 \%$ \\
\hline & $p=0.05$ & NS & $p=0.07$ \\
\hline \multirow{3}{*}{$\begin{array}{l}\text { Pooled effect* } \\
\text { Three FBAT programs } \\
\text { covering entire community }\end{array}$} & 0.70 & 0.75 & 0.66 \\
\hline & $(0.53-0.93)$ & $(0.55-1.03)$ & $(0.44-0.98)$ \\
\hline & $\begin{array}{l}\text { Relative reduction } 30 \% \\
p=0.01\end{array}$ & $\begin{array}{l}\text { Relative reduction } 25 \% \\
p=0.08\end{array}$ & $\begin{array}{l}\text { Relative reduction } 34 \% \\
p=0.04\end{array}$ \\
\hline \multirow{2}{*}{$\begin{array}{l}\text { Seven FB communities not } \\
\text { targeting alcohol } \\
\text { availability and increased } \\
\text { treatment* }\end{array}$} & $1.17(0.90-1.52)$ & $1.23(1.03-1.47)$ & $1.18(0.95-1.46)$ \\
\hline & $\begin{array}{l}\text { Relative increase } 17 \% \\
\text { NS }\end{array}$ & $\begin{array}{l}\text { Relative increase } 23 \% \\
p=0.02\end{array}$ & $\begin{array}{l}\text { Relative increase } 18 \% \\
\text { NS }\end{array}$ \\
\hline \multicolumn{4}{|c|}{$\begin{array}{l}\text { *No significant heterogeneity was found for pooled analyses of five } \mathrm{FB} \text { communities or three } \mathrm{FB} \text { communities at } \\
\mathrm{BAC} \text { levels of } 0.01 \%+, 0.08 \%+\text {, or } 0.15 \%+\text {. Pooled analysis of } \mathrm{FB} \text { communities not targeting alcohol availability } \\
\text { and increased treatment found significant heterogeneity of program effects at BAC level of } 0.01 \%+\text {. } \\
\text { NS, not significant. }\end{array}$} \\
\hline
\end{tabular}


on these outcomes across these five FB communities was not statistically significant.

In the three FBAT communities that targeted the entire city (Milwaukee, Santa Barbara, and Vallejo), there were declines of $30 \%$ in the odds of drivers in fatal crashes with $0.01 \%$ BAC or higher $(p=0.01), 25 \%$ with $0.08 \%$ BAC or higher $(p=0.08)$, and a 34\% decline in the odds of drivers in fatal crashes with $0.15 \%$ BAC or higher, relative to zero BAC $(p=0.04)($ table 5$)$. Of note, these decreases exceeded what was observed when all five FBAT communities were analyzed collectively.

In the other FB communities with less concentrated efforts to reduce alcohol availability and increase substance abuse treatment, there were no declines in the odds of drivers with BACs of $0.01 \%$ or higher, $0.08 \%$ or higher, and $0.15 \%$ and higher, relative to zero BAC.

\section{DISCUSSION}

FBAT communities that mounted concentrated efforts to expand substance abuse treatment and limit alcohol availability experienced significant declines in alcohol related fatal traffic crashes. The declines were greatest for those communities that targeted the entire city. In contrast, no declines were found in FB communities with less concentrated efforts.

Several factors should be considered when interpreting these results. First, our assessment of actions to limit alcohol availability and expand treatment services was conducted retrospectively, mostly through archival program and evaluation documents. We were unable to quantify the individuals exposed to the actions or ascertain the magnitude or duration of implementation.

Second, communities that apply for grants may be more motivated and better organized to prevent substance abuse problems. One study design to control for this would divide communities with high quality proposals into intervention on comparison communities and also make comparisons with other communities that did not apply for funding. The Fighting Back evaluation team did not attempt such a comparison, making it difficult to assess whether the motivation and organization to prepare a high quality proposal would be sufficient by itself to reduce alcohol related traffic crashes.

Third, the Fighting Back communities other than the FBAT communities pursued strategies that were not shown by previous research to specifically reduce alcohol related traffic deaths. These included school based substance abuse curricula, community development, youth leadership development, and community policing. These strategies were implemented to address substance abuse related harms other than alcohol related traffic crashes. It is not surprising that they did not experience reductions in alcohol related traffic deaths.

Fourth, while many FBAT activities in study communities continue, it is too early to ascertain whether they will be institutionalized and accompanied by longer term declines in alcohol related fatal crash declines.

Fifth, the FARS system allows comparisons at the community level, not the neighborhood level. However, the similarity in the pre-program proportions and trends for fatal crashes that involved alcohol at $0.01 \%, 0.08 \%$, and $0.15 \%$ $\mathrm{BAC}$, and for drivers with BACs at those levels, suggest that these were appropriate comparison selections.

Sixth, we used a meta-analytic statistical approach, which is becoming increasingly popular in medical research where information on the efficacy of a treatment is available from a number of clinical studies with similar treatment protocols. Combining available evidence about treatment efficiency across such studies represents an attractive analysis alternative because it enhances statistical power. ${ }^{22}$ Caution should be used when integrating results from studies that are diverse in design and methods. In this analysis, FBAT programs were initiated during the same year in each city and used exactly the same outcome measures, comparison site selection criteria, and analysis time periods. We recognize, however, some variability in program implementation even in the five FBAT communities.

Seventh, FBAT communities identified as having concentrated efforts to reduce alcohol availability and increase treatment implemented eight or more strategies to achieve these objectives. To assess whether more intensive implementation of fewer strategies could have achieved different alcohol related fatal crash declines, future evaluations should include more precise process measures of program implementation, such as actual numbers and percentages of people needing substance abuse treatment who receive it.

Eighth, heightened police enforcement of drinking driving laws-particularly the use of publicized sobriety checkpoints-can reduce alcohol related crashes and deaths. ${ }^{23}$ However, only Santa Barbara intensified police enforcement of drink driving laws. The lack of specific new emphasis on this by the other four FBAT communities actually raises our confidence that their efforts to reduce alcohol availability and increase treatment were key factors in reducing alcohol involvement in fatal crashes. Of note, Santa Barbara had similar alcohol related fatal crash declines as those other FBAT communities. The combined impact of publicized enforcement of drinking driving laws using checkpoints with interventions to reduce alcohol availability and increase substance use treatment warrants future investigation.

Ninth, we selected $0.01 \%$ BAC or higher as the lowest cut off for alcohol related fatal crash involvement because a recent review of 112 studies provided evidence that impairment in driving skills begins with any departure from zero BAC. ${ }^{24}$ The majority of studies reported impairment by $0.05 \%$ BAC. Virtually all drivers tested in these studies exhibited impairment on some critical driving measure by the time they reached $0.08 \%$ BAC.

Importantly, reductions in the ratio of alcohol related to non-alcohol related fatal crashes were found at all three BAC levels, including the highest level: $22 \%$ at $0.01 \%$ or higher, $20 \%$ at $0.08 \%$ or higher, and $17 \%$ at $0.15 \%$ or higher. Because a sizable majority of people in alcohol related crashes are alcohol dependent and would benefit from treatment, an intervention to increase substance abuse treatment could achieve such a broad effort.

If the FBAT program interventions were effective, programs targeting an entire community versus only part of a community should have seen greater proportional declines in the ratio of alcohol related to non-alcohol related fatal crashes. This was the case. At $0.08 \%$ BAC or higher, the three FBAT programs targeting an entire community saw a $36 \%$ reduction relative to their respective comparison sites, while all five FB programs together saw a $20 \%$ reduction. Likewise, at $0.15 \%$ BAC or higher, the decline was $39 \%$ in FBAT communities targeting the entire community, relative to $17 \%$ for all five FB programs together.

The proportional decline in alcohol related crashes achieved by these interventions exceeds the $6-8 \%$ declines attributable to lowering legal blood alcohol limits to $0.08 \%$ where enforcement levels varied across communities. ${ }^{25-27}$ In contrast, the five FBAT communities were known to have implemented the target interventions.

Declines in alcohol related fatal crashes or drivers with positive BAC in fatal crashes were observed only in the five of 12 FB communities, the FBAT communities with concentrated efforts to reduce alcohol availability and increase substance abuse treatment. As literature accumulates about what types of community interventions successfully reduce alcohol related problems, communities can focus on 


\section{Key points}

- Five of 14 communities awarded Robert Wood Johnson Foundation grants to reduce substance abuse and related problems undertook concentrated efforts to reduce availability of alcohol and expand substance abuse treatment programs (FBAT communities).

- Relative to matched comparison communities in the same state, the five FBAT communities experienced significant declines in alcohol related fatal crashes relative to fatal crashes not involving alcohol during the 10 years of the program compared with the 10 previous years.

- Community organizing interventions may not be sufficient to reduce alcohol related problems unless they specifically identify and implement interventions that have previously had demonstrable benefits or that have a plausible rationale for reducing alcohol related problems.

- Community interventions to reduce alcohol availability and increase substance abuse treatment can reduce alcohol related fatal traffic crashes.

intervention strategies likely to produce desired results. Community organizing interventions may not be sufficient to reduce alcohol related problems unless they specifically identify and implement interventions that have previously had demonstrable benefits or that have a plausible rationale for reducing alcohol related problems.

\section{Authors' affiliations}

R W Hingson, R C Zakocs, T Heeren, M R Winter, D Rosenbloom, W DeJong, Boston University School of Public Health and Center to Prevent Alcohol-related Problems Among Young People, Boston, MA, USA

Supported by the National Institute on Alcohol Abuse and Alcoholism

\section{REFERENCES}

1 Hingson R, Winter M. Epidemiology and consequences of drinking and driving. Alcohol Res Health 2003;27:63-78.

2 Hingson R, Howland J. Comprehensive community interventions to promote health: implications for college-age drinking problems. J Stud Alcohol 2002; S14:226-40.

3 National Institute on Alcoholism and Alcohol Abuse Task Force of the National Advisory Council. A call to action: changing the culture of drinking at U.S. colleges, NIH Publication No 02-5010, 2002.
4 Institute of Medicine. Reducing underage drinking: a collective responsibility. Washington DC: The National Academies Press, 2004

5 Hingson RW, McGovern T, Howland J, et al. Reducing alcohol-impaired driving in Massachusetts: the Saving Lives Program. Am J Public Health 1996:86:791-7.

6 Holder HD, Gruenwald PJ, Ponicki WR, et al. Effect of community-based interventions on high-risk drinking and alcohol-related injuries. JAMA 2000;284:2341-7.

7 Wagenaar AC, Murray DM, Cohan JP, et al. communities mobilizing for change: outcomes from a randomized community trial on arrest and traffic crashes. Addiction 2000;95:209-17.

8 Spirito A, Monti PM, Barnett NP, et al. A randomized clinical trial of a brief motivational intervention for alcohol-positive adolescents treated in an emergency department. J Pediatr 2004;145:396-402.

9 Longabaugh R, Woolard RF, Nirenberg TD, et al. Evaluating the effects of a brief motivational intervention for injured drivers in the emergency department. J Studies on Alcohol 2001;62:806-16.

10 Crawford MJ, Patton R, Touquet R, et al. Screening and referral for brief intervention of alcohol-misusing patients in an emergency department: a pragmatic randomised controlled trial. Lancet 2004;364:1334-9.

11 Dill PL, Wells-Parker E, Soderstrom CA. The emergency care setting for screening and intervention for alcohol use problems among injured and highrisk drivers: a review. Traffic Inj Prev 2004;5:278-91.

12 Gentilello LM, Rivara FP, Donovan DM, et al. Alcohol interventions in a trauma center as a means of reducing the risk of injury reoccurrence. Ann Surg 1999;230:437-83

13 Monti PM, Colby SM, Barnett NP, et al. Brief intervention for harm reduction with alcohol-positive older adolescents in a hospital emergency room. J Consult Clin Psychol 1999;67:989-94.

14 Whitlock EP, Polen MR, Green CA, et al. U.S. Preventive Services Task Force. Behavioral counseling interventions in primary care to reduce risky/harmful alcohol use by adults: a summary of the evidence for the U.S. Preventive Services Task Force. Ann Intern Med 2004; 140:557-68.

15 Dinh-Zarr T, DiGuiseppi C, Heitman E, et al. Preventing injuries through interventions for problem drinking: A systematic review of randomized controlled trials. Alcohol Alcohol 1999;34:609-21.

16 Wells-Parker E, Bangert-Drowns R, McMillen R, et al. Final results from a meta-analysis of remedial interventions with drink/drive offenders. Addiction 1995;90:907-26.

17 Center for Substance Abuse Prevention (2000). Prevention works through community partnerships: findings from SAMHSA/CSAP's national evaluation Washington, DC: Substance Abuse and Mental Health Services Administration (SAMSHA) DHHS Publication No (SMA) 00-3373, 2000

18 Crowely KM, Yu P, Kaftarian SJ. Prevention actions and activities make a difference: a structural equation model of coalition-building. Eval Program Plann 2000;23:381-8.

19 Jellinek PS, Hearn RP. Fighting drug abuse at the local level. Issues Sci Technol 1991;7:78-84

20 Spickard WA Jr, Dixon GL, Sarver FW. Fighting back against America's public enemy number one. Bull NY Acad Med 1994;71:111-35.

21 Kadushin C, Saxe L, Livert D, et al. Fighting back household survey: interim report of 1995-1999 findings. Waltham, MA: Brandeis University, 2000.

22 Der Simonian R, Laird N. Meta-analysis in clinical trials. Control Clin Trials 1986;7:177-88.

23 Fell JC, Lacey JH, Voas RB. Sobriety checkpoints: evidence of effectiveness is strong, but use is limited. Traffic Inj Prev 2004;5:220-8

24 Moskowitz $\mathrm{H}$, Fiorentino D. A review of the literature of the effects of low doses of alcohol on driving related skills April 2000. U.S. Department of Transportation DOT HS 809-028, 2000

25 Voas R, Tippetts A, Fell J. The relationship of alcohol safety laws to drinking drivers in fatal crashes. Accid Anal Prev 2000;32:482-93.

26 Hingson $\mathbf{R}$, Heeren T, Winter M. Effects of recent 0.08 percent legal blood alcohol limits on fatal crash involvement. Inj Prev 2000;6:109-14.

27 Shults S, Elder R, Sleet D, et al. Reviews of evidence regarding interventions to reduce alcohol impaired driving. Am J Prev Med 2001;21(Suppl 4):66-88. 